\title{
Avaliação de habilidades de linguagem e pessoal-sociais pelo Teste de Denver II em instituições de educação infantil*
}

\author{
Magda Andrade Rezende ${ }^{1}$ \\ Vivian César Beteli \\ Jair Lício Ferreira dos Santos ${ }^{3}$
}

\begin{abstract}
Rezende MA, Beteli VC, Santos JLF. Avaliação de habilidades de linguagem e pessoalsociais pelo Teste de Denver II em instituições de educação infantil. Acta Paul Enferm 2005; 18(1):56-63.
\end{abstract}

\begin{abstract}
RESUMO: Supervisão e promoção do desenvolvimento infantil são cuidados necessários às crianças que freqüentam creches e pré-escolas. Organizações de saúde internacionais e nacionais têm sistematizado estratégias para tal, porém nas instituições brasileiras estas ações são pouco realizadas. Objetivo: Avaliar, pelo segundo ano consecutivo, habilidades das áreas de linguagem e pessoal-social de uma coorte de crianças que freqüentam 3 creches da cidade de São Paulo. Método: O grupo amostral foi constituído por 30 crianças de 0 a 4 anos, de nível sócio-econômico homogêneo segundo instrumento para avaliação de nível de pobreza urbana. Segundo este instrumento todas as famílias estavam na faixa superior de classificação. Para avaliação do desenvolvimento foi usado o Teste de Triagem de Desenvolvimento de Denver II, empregado em dois momentos distintos no primeiro ano de acompanhamento da coorte, e uma vez no segundo ano. Resultados: $\mathrm{Na}$ área pessoal-social a melhora foi significante da $1^{\mathrm{a}}$ para a $2^{\mathrm{a}}$ avaliação, o que não ocorreu na área de linguagem, ao longo das 3 avaliações. No entanto, a partir dos 3 anos de idade as crianças passaram a obter resultados piores. Quanto aos sexos não houve diferenças significantes nos desempenhos nas duas áreas. Conclusão: É possível que as habilidades das crianças na área pessoal-social tenham sido incrementadas pelas condições das instituições, o que não ocorreu na de linguagem. Não se pode afirmar a causa destes acontecimentos, embora seja intrigante a proporção adulto/criança que diminui após as crianças completarem 3 anos de idade, mas outras pesquisas são necessárias, inclusive a continuidade desta coorte.
\end{abstract}

Descritores: Creches; Educação infantil; Cuidado da criança; Desenvolvimento infantil; Linguagem infantil

- Artigo recebido em 16/07/04 e aprovado em 10/12/04

\section{SUPERVISÃO DO \\ DESENVOLVIMENTO INFANTIL}

Creches e pré-escolas são instituições destinadas a educar e cuidar de crianças. As primeiras atendem a faixa etária de 0 a 3 anos de idade, e as outras daí em diante, até 6 anos. Nestes locais é necessário supervisionar o desenvolvimento infantil, e organismos nacionais e internacio- nais têm sistematizado esta ação ${ }^{(1-3)}$. Entretanto, na maior parte de creches e pré-escolas brasileiras, a supervisão do desenvolvimento infantil vem sendo realizada de modo eventual, segundo a bibliografia e a nossa experiência.

O número de crianças que freqüentam creches e pré-escolas aumenta dia a dia em nosso país. Em 2003, havia oficialmente 6.393.234 crianças matriculadas nestas instituições. As crianças menores, que freqüentam as creches são as que permanecem mais tempo: quase oito horas por dia. Considerando, inclusive, a vulnerabilidade desta idade compreende-se a importância da capacitação dos adultos que cuidam e educam estas crianças, bem como da organização do ambiente físico.

1 Pesquisa parcialmente financiada pela Fapesp (processo 00/11890-7) e pelo CNPq (projeto 248/2002).

* Professora Doutora do Departamento de Enfermagem Materno-Infantil e Psiquiátrica da Escola de Enfermagem da Universidade de São Paulo. Orientadora do trabalho. E-mail: marezend@yahoo.com.br

** Enfermeira. Mestranda vinculada ao programa de pós-graduação da Escola de Enfermagem da Universidade de São Paulo.

*** Professor Titular do Departamento de Medicina Social da Faculdade de Medicina de Ribeirão Preto da Universidade de São Paulo. 
Nas habilidades pessoal-sociais e de linguagem, como nas outras áreas do desenvolvimento, as crianças dependem das oportunidades oferecidas pelo ambiente para desenvolverem plenamente sua herança genética. Ou seja, o desenvolvimento é um produto da interação dessa com o meio, constituindo o chamado interacionismo ${ }^{(4-5)}$. $\mathrm{Na}$ área pessoal-social valoriza-se a conquista da independência da criança para realizar tarefas cotidianas e importantes como lavar as mãos, alimentar-se e escovar os dentes, por exemplo. Segundo o Referencial Curricular para a Educação Infantil as creches e pré-escolas devem criar condições para que as crianças se interessem progressivamente pelo cuidado com o próprio corpo, executando ações relacionadas à saúde e à higiene ${ }^{(6)}$. No que diz respeito à linguagem ${ }^{(7)}$, importante para que a criança possa resolver problemas e planejar suas ações, o mesmo documento propõe um ambiente de acolhimento que dê segurança e confiança às crianças, garantindo oportunidades para que experimentem e usem recursos para a satisfação de suas necessidades, expressando desejos, sentimentos, vontades e desagrados. Assim, a supervisão do desenvolvimento infantil é um cuidado à saúde da criança e diz respeito, inclusive, à área de enfermagem, motivo pelo qual se propõe a sistematização desta ação em creches e pré-escolas, a fim de se otimizar os fatores ambientais (isto é, adultos e condições físicas) na promoção do desenvolvimento.

\section{OBJETIVO}

Observar de modo sistematizado habilidades das áreas de linguagem e pessoal-social de uma coorte de crianças consideradas normais que freqüentam creches de bom padrão de qualidade da cidade de São Paulo

\section{MÉTODO}

\section{Cenário do estudo}

As 3 instituições, que atendem a crianças de 0 a 6 anos, cumprem vários critérios de bom atendimento: organização das crianças em pequenos grupos, bom nível de educação e treinamento dos adultos, baixa rotatividade destes, estabilidade administrativa e índice remuneração mais alto do que a média local (5). Estão localizadas próximas umas das outras, na região oeste do município de São Paulo.

\section{Grupo amostral}

Compuseram a amostra intencional $^{(8)}$ todas as crianças que preenchiam os critérios de inclusão (idade gestacional conhecida, no caso de menores de 2 anos; ausência de mal formação congênita; não ter freqüentado creche anteriormente, e não ser estrangeira, devido à avaliação da área de linguagem). Este grupo vem sendo avaliado desde 2001, e conta, atualmente, com 30 crianças.

\section{O Teste de Triagem de Desenvolvi- mento de Denver II (TTDD II)}

O TTDD II foi elaborado para que profissionais da área de saúde fizessem a triagem de desenvolvimento em crianças de 0 a 6 anos. É composto por 125 itens, divididos nas áreas: pessoal-social, motor finoadaptativo, linguagem e motor-grosseiro. Para alguns itens pede-se que a criança realize determinadas tarefas, para outros se considera o relato dos responsáveis ${ }^{(9)}$.

Consideramos fatores de exclusão transitórios: sono, fadiga, febre ou medo. Nestas situações aguardamos até que fossem superados. A aplicação era interrompida caso a criança se cansasse ou precisasse participar de alguma atividade. Nas situações em que a criança estranhava, pedia-se à educadora com a qual a criança estava acostumada que ficasse junto. Deste modo a aplicação do TTDD II pode ser bastante demorada. Mas, é importante que ocorram estes cuidados para que a criança se sinta segura e a aplicação fidedigna. O modo de aplicação do TTDD II já foi detalhado ${ }^{(10)}$.

Cada um dos itens avaliados é classificado em: normal, cautela ou atraso. Normal: quando a criança executa atividade prevista para a idade. Cautela: quando a criança não executa ou recusa-se a realizar atividade que já é feita por 75 a $90 \%$ das crianças daquela idade. Atraso: quando a criança não executa ou recusa-se a realizar atividade que já é executada por mais de $90 \%$ dos que têm sua idade $^{(11)}$. A classificação destes itens é que foi usada para esta pesquisa. Os resultados obtidos: normal, cautela ou atraso foram agrupados em adequado (normal) e não adequado (cautela e/ou atraso). O TTDD II não foi criado para diagnosticar atrasos no desenvolvimento, e sim direcionar o cuidado dos adultos para as crianças com riscos ${ }^{(9)}$.

\section{Cuidados éticos e análise das informações}

O projeto foi aprovado por Comitê de Ética em Pesquisa conforme Portaria 196/96. A análise foi realizada com testes não-paramétricos de Fisher, Wilcoxon e Teste dos sinais, que são usados em situações em que as mensurações são categóricas, ou, no máximo, ordinais. Isto é, não é necessário que a distribuição seja gaussiana ${ }^{(12)}$. Assumiu-se risco a de $5 \%{ }^{(13)}$.

\section{RESULTADOS E DISCUSSÃO}

As crianças foram avaliadas 3 vezes: na $1^{\text {a }}$ suas idades variaram de 4 meses e 23 dias até 2 anos 4 meses e 12 dias. Na $2^{a}$ suas idades foram de 10 meses e 20 dias até 2 anos 10 meses e 28 dias. Na $3^{\mathrm{a}}$ tinham de 2 anos e 15 dias até 4 anos. Na pri- 
meira avaliação estavam freqüentando as creches por períodos que variavam de 1 dia até 5 meses, o que não deve ter interferido nos resultados pois esta pesquisa não foi desenhada com o fim de se distinguir entre as influências respectivas da família e da instituição. O intervalo entre as duas primeiras avaliações foi de aproximadamente 6 meses e entre a $2^{\mathrm{a}}$ e a $3^{\mathrm{a}}$ cerca de 1 ano. $\mathrm{O}$ grupo é formado por 17 meninos e 13 meninas.

O nível sócio-econômico foi avaliado segundo instrumento para verificação do nível de pobreza de populações urbanas, composto por 13 itens: constituição da família, escolaridade e atividade dos pais, condições de moradia e posse de bens. Cada um dos itens é pontuado e a soma estabelece o nível de pobreza: miséria (até 17,3 pontos), baixo inferior (17,3 a 34,6 pontos) e baixo superior (34,6 a
52,0 pontos) $)^{(14)}$. Neste grupo todas as famílias tiveram pontuação entre 45 e 52. Assim, todas são da categoria baixa superior.

Sabe-se da importância das condições ambientais e do nível sócioeconômico na possibilidade da criança desenvolver suas habilidades. Assim, avaliação de desenvolvimento realizada em Pelotas (RS) feita com uso do TTDD II, mostrou relação positiva entre possíveis atrasos de desenvolvimento e diminuição da renda familiar ${ }^{(15)}$. Em outro estudo, que avaliou o desenvolvimento de crianças de 0 a 13 meses de idade, não houve relação significante entre desenvolvimento e condição econômica ${ }^{(16)}$. Além disto, pesquisa realizada nos EUA em 10 cidades, destinada a avaliar os efeitos dos diferentes tipos de cuidados à criança de 6 até 36 meses de idade (creche, creche domiciliar, cuidada pelos pais), mostrou não haver relação entre desenvolvimento e renda familiar ${ }^{(17)}$. Como se vê os resultados ainda são controversos e podem estar relacionados às diferentes metodologias empregadas, uma vez que se sabe da importância da inserção social e renda nas oportunidades de desenvolvimento que a família pode oferecer à criança.

\section{Área pessoal-social}

A tabela 1 mostra os resultados de cada criança nas três avaliações. Na primeira, 24 (80\%) resultados foram adequados e 6 (20\%) eram cautelas ou atrasos. Na segunda, 30 (100\%) estavam adequados. Na terceira, 28 (93,33\%) estavam adequadas e 2 (6,67\%) não, havendo portanto, melhora em relação à primeira avaliação e discreta piora em relação à segunda.

Tabela 1 - Resultados emparelhados das avaliações da área pessoal-social pelo Teste de Denver II de crianças de 3 creches. (São Paulo, 2001-2003).

\begin{tabular}{|c|c|c|c|}
\hline Criança & $1^{\text {a }}$ Avaliação & $2^{\text {a }}$ Avaliação & $3^{\text {a }}$ Avaliação \\
\hline $\begin{array}{c}1 \\
2 \\
3 \\
4 \\
5 \\
6 \\
7 \\
8 \\
9 \\
10 \\
11 \\
12 \\
13 \\
14 \\
15 \\
16 \\
17 \\
18 \\
19 \\
20 \\
21 \\
22 \\
23 \\
24 \\
25 \\
26 \\
27 \\
28 \\
29 \\
30\end{array}$ & $\begin{array}{c}1 \text { Cautela } \\
1 \text { Cautela } \\
\text { Adequada } \\
1 \text { Cautela } \\
\text { Adequada } \\
1 \text { Atraso } \\
\text { Adequada } \\
\text { Adequada } \\
\text { Adequada } \\
\text { Adequada } \\
\text { Adequada } \\
\text { Adequada } \\
\text { Adequada } \\
\text { Adequada } \\
\text { Adequada } \\
\text { Adequada } \\
1 \text { Cautela } \\
\text { Adequada } \\
\text { Adequada } \\
\text { Adequada } \\
\text { Adequada } \\
\text { Adequada } \\
\text { Adequada } \\
\text { Adequada } \\
\text { Adequada } \\
1 \text { Cautela } \\
\text { Adequada } \\
\text { Adequada } \\
\text { Adequada } \\
\text { Adequada }\end{array}$ & $\begin{array}{l}\text { Adequada } \\
\text { Adequada } \\
\text { Adequada } \\
\text { Adequada } \\
\text { Adequada } \\
\text { Adequada } \\
\text { Adequada } \\
\text { Adequada } \\
\text { Adequada } \\
\text { Adequada } \\
\text { Adequada } \\
\text { Adequada } \\
\text { Adequada } \\
\text { Adequada } \\
\text { Adequada } \\
\text { Adequada } \\
\text { Adequada } \\
\text { Adequada } \\
\text { Adequada } \\
\text { Adequada } \\
\text { Adequada } \\
\text { Adequada } \\
\text { Adequada } \\
\text { Adequada } \\
\text { Adequada } \\
\text { Adequada } \\
\text { Adequada } \\
\text { Adequada } \\
\text { Adequada } \\
\text { Adequada }\end{array}$ & $\begin{array}{c}\text { Adequada } \\
\text { Adequada } \\
\text { Adequada } \\
\text { Adequada } \\
\text { Adequada } \\
\text { Adequada } \\
\text { Adequada } \\
\text { Adequada } \\
\text { Adequada } \\
\text { Adequada } \\
\text { Adequada } \\
\text { Adequada } \\
\text { Adequada } \\
\text { Adequada } \\
\text { Adequada } \\
\text { Adequada } \\
\text { Adequada } \\
\text { Adequada } \\
\text { Adequada } \\
\text { Adequada } \\
\text { Adequada } \\
\text { 1 Cautela } \\
\text { Adequada } \\
\text { Adequada } \\
1 \text { Atraso } \\
\text { Adequada } \\
\text { Adequada } \\
\text { Adequada } \\
\text { Adequada } \\
\text { Adequada }\end{array}$ \\
\hline
\end{tabular}

Teste dos sinais 
Após, foram feitos três tipos de comparações (a $1^{\text {a }}$ com a $2^{\mathrm{a}}$ avaliação, a $2^{\mathrm{a}} \mathrm{com}$ a $3^{\mathrm{a}}$ e a $1^{\mathrm{a}} \operatorname{com}$ a $3^{\mathrm{a}}$ avaliação) para aplicação do teste dos sinais. Quando não houve alteração, foi nomeado empate. Nos casos de mudança de cautela ou atraso para adequada considerou-se sinal positivo e ao contrário negativo.

Da $1^{a}$ para a $2^{a}$ avaliação, houve incremento significante da área, seguido de estabilização.
Os resultados obtidos nos 3 momentos foram agrupados de acordo com o sexo, não tendo havido diferença significante (Teste exato de Fisher, $\mathrm{P}=0$,516). Este resultado contrasta com estudo realizado na Turquia entre 1995 e 1996 com 1091 crianças, em que meninas obtiveram melhores resultados ${ }^{(18)}$.

\section{Área de linguagem}

As informações estão na Tabela 2. Na primeira avaliação 23 (76,67\%) resultados foram adequados e 7 (23,33\%) não. Na segunda houve 25 adequações (83,33\%), e 5 $(16,67 \%)$ cautelas. Na terceira avaliação, 22 (73,33\%) foram adequados e $8(26,67 \%)$ cautelas. Ao teste dos sinais os resultados não foram significantes, isto é, não houve alterações entre os diferentes períodos.

Tabela 2 - Resultados emparelhados das avaliações da área de linguagem pelo Teste de Denver II de crianças em 3 creches. (São Paulo, 2001-2003)

\begin{tabular}{|c|c|c|c|}
\hline Criança & $1^{a}$ Avaliação & $2^{\mathrm{a}}$ Avaliação & $3^{\text {a }}$ Avaliação \\
\hline $\begin{array}{c}1 \\
2 \\
3 \\
4 \\
5 \\
6 \\
7 \\
8 \\
9 \\
10 \\
11 \\
12 \\
13 \\
14 \\
15 \\
16 \\
17 \\
18 \\
19 \\
20 \\
21 \\
22 \\
23 \\
24 \\
25 \\
26 \\
27 \\
28 \\
29 \\
30\end{array}$ & $\begin{array}{c}1 \text { Cautela } \\
1 \text { Cautela } \\
1 \text { Cautela }+1 \text { Atraso } \\
\text { Adequada } \\
\text { Adequada } \\
\text { Adequada } \\
\text { Adequada } \\
\text { Adequada } \\
\text { Adequada } \\
\text { Adequada } \\
\text { Adequada } \\
\text { Adequada } \\
\text { Adequada } \\
\text { Adequada } \\
1 \text { Cautela } \\
\text { Adequada } \\
\text { Adequada } \\
\text { Adequada } \\
1 \text { Cautela }+1 \text { Atraso } \\
\text { Adequada } \\
\text { Adequada } \\
\text { Adequada } \\
\text { Adequada } \\
\text { Adequada } \\
1 \text { Cautela } \\
\text { Adequada } \\
\text { Adequada } \\
\text { Adequada } \\
\text { Adequada } \\
1 \text { Cautela }\end{array}$ & $\begin{array}{l}\text { Adequada } \\
\text { Adequada } \\
\text { Adequada } \\
\text { Adequada } \\
\text { Adequada } \\
\text { Adequada } \\
\text { Adequada } \\
\text { Adequada } \\
\text { Adequada } \\
\text { Adequada } \\
\text { Adequada } \\
\text { Adequada } \\
\text { Adequada } \\
\text { Adequada } \\
\text { Adequada } \\
\text { Adequada } \\
1 \text { Cautela } \\
\text { Adequada } \\
\text { Adequada } \\
\text { Adequada } \\
1 \text { Cautela } \\
1 \text { Cautela } \\
\text { Adequada } \\
\text { Adequada } \\
\text { Adequada } \\
1 \text { Cautela } \\
\text { Adequada } \\
\text { Adequada } \\
1 \text { Cautela } \\
\text { Adequada }\end{array}$ & $\begin{array}{l}\text { Adequada } \\
\text { Adequada } \\
\text { Adequada } \\
\text { Adequada } \\
\text { Adequada } \\
\text { Adequada } \\
1 \text { Cautela } \\
1 \text { Cautela } \\
4 \text { Cautelas } \\
1 \text { Cautela } \\
1 \text { Cautela } \\
2 \text { Cautelas } \\
1 \text { Cautela } \\
\text { Adequada } \\
\text { Adequada } \\
\text { Adequada } \\
\text { Adequada } \\
\text { Adequada } \\
\text { Adequada } \\
\text { Adequada } \\
\text { Adequada } \\
1 \text { Cautela } \\
\text { Adequada } \\
\text { Adequada } \\
\text { Adequada } \\
\text { Adequada } \\
\text { Adequada } \\
\text { Adequada } \\
\text { Adequada } \\
\text { Adequada }\end{array}$ \\
\hline
\end{tabular}

Teste dos sinais

1 e 2 P=0,387 não significante 2 e 3 P=0,274 não significante 1 e 3 P=0,696 não significante

Os resultados foram analisados em relação à idade das crianças (Tabela 3). Percebe-se que as cau- telas começam após os 3 anos de idade, atingindo 8 das 10 crianças, o que foi significante pelo teste de
Fischer $(\mathrm{P}=0,00001)$. Destas, 7 freqüentavam a mesma creche. 
Tabela 3 - Resultados da $3^{\mathrm{a}}$. avaliação da área de linguagem das crianças de 3 creches segundo seus valores crescentes de idade. São Paulo, 2002-2003.

\begin{tabular}{|c|c|c|c|c|}
\hline \multirow[b]{2}{*}{ Criança } & \multirow[b]{2}{*}{ Idade } & \multirow[b]{2}{*}{$3^{a}$ Avaliação } & \multicolumn{2}{|c|}{ Idades } \\
\hline & & & Dias & Anos \\
\hline 24 & 2a $15 d$ & Adequada & 745 & 2,04 \\
\hline 25 & $2 \mathrm{a} 1 \mathrm{~m} 10 \mathrm{~d}$ & Adequada & 770 & 2,11 \\
\hline 15 & $2 \mathrm{a} 1 \mathrm{~m} 20 \mathrm{~d}$ & Adequada & 780 & 2,14 \\
\hline 26 & $2 \mathrm{a} 1 \mathrm{~m} 24 \mathrm{~d}$ & Adequada & 784 & 2,15 \\
\hline 27 & $2 \mathrm{a} 2 \mathrm{~m}$ & Adequada & 790 & 2,16 \\
\hline 28 & $2 \mathrm{a} 2 \mathrm{~m}$ & Adequada & 790 & 2,16 \\
\hline 29 & $2 \mathrm{a} 2 \mathrm{~m} 14 \mathrm{~d}$ & Adequada & 1169 & 2,20 \\
\hline 16 & $2 \mathrm{a} 4 \mathrm{~m} 8 \mathrm{~d}$ & Adequada & 858 & 2,35 \\
\hline 17 & $2 \mathrm{a} 4 \mathrm{~m} 29 \mathrm{~d}$ & Adequada & 879 & 2,41 \\
\hline 1 & $2 \mathrm{a} 6 \mathrm{~m} 9 \mathrm{~d}$ & Adequada & 919 & 2,52 \\
\hline 2 & $2 \mathrm{a} 6 \mathrm{~m} \mathrm{9d}$ & Adequada & 919 & 2,52 \\
\hline 18 & $2 \mathrm{a} 6 \mathrm{~m} 12 \mathrm{~d}$ & Adequada & 922 & 2,53 \\
\hline 19 & $2 \mathrm{a} 6 \mathrm{~m} 27 \mathrm{~d}$ & Adequada & 937 & 2,57 \\
\hline 3 & $2 \mathrm{a} 7 \mathrm{~m} 21 \mathrm{~d}$ & Adequada & 961 & 2,63 \\
\hline 4 & $2 \mathrm{a} 7 \mathrm{~m} 24 \mathrm{~d}$ & Adequada & 964 & 2,64 \\
\hline 30 & $2 \mathrm{a} 8 \mathrm{~m} 8 \mathrm{~d}$ & Adequada & 978 & 2,68 \\
\hline 21 & $2 \mathrm{a} 9 \mathrm{~m} 7 \mathrm{~d}$ & Adequada & 1007 & 2,76 \\
\hline 20 & $2 \mathrm{a} 9 \mathrm{~m} 14 \mathrm{~d}$ & Adequada & 1014 & 2,78 \\
\hline 5 & $2 \mathrm{a} 11 \mathrm{~m} 7 \mathrm{~d}$ & Adequada & 1067 & 2,92 \\
\hline 6 & $2 \mathrm{a} 11 \mathrm{~m} 13 \mathrm{~d}$ & Adequada & 1074 & 2,94 \\
\hline 22 & $3 \mathrm{a} 1 \mathrm{~m} \mathrm{2d}$ & 1 Cautela & 1127 & 3,09 \\
\hline 7 & $3 \mathrm{a} 1 \mathrm{~m} \mathrm{10d}$ & 1 Cautela & 1135 & 3,11 \\
\hline 8 & $3 \mathrm{a} 2 \mathrm{~m} 25 \mathrm{~d}$ & 1 Cautela & 1180 & 3,23 \\
\hline 9 & $3 \mathrm{a} 5 \mathrm{~m} \mathrm{24d}$ & 4 Cautelas & 1269 & 3,48 \\
\hline 10 & $3 \mathrm{a} 6 \mathrm{~m} 2 \mathrm{~d}$ & 1 Cautela & 1277 & 3,50 \\
\hline 11 & $3 \mathrm{a} 8 \mathrm{~m} \mathrm{13d}$ & 1 Cautela & 1348 & 3,69 \\
\hline 12 & $3 \mathrm{a} 8 \mathrm{~m} 24 \mathrm{~d}$ & 2 Cautelas & 1359 & 3,72 \\
\hline 23 & $3 \mathrm{a} 9 \mathrm{~m} 22 \mathrm{~d}$ & Adequada & 1387 & 3,80 \\
\hline 13 & $3 \mathrm{a} 10 \mathrm{~m} \mathrm{od}$ & 1 Cautela & 1405 & 3,85 \\
\hline 14 & $3 \mathrm{a} 11 \mathrm{~m} 5 \mathrm{~d}$ & Adequada & 1430 & 3,92 \\
\hline
\end{tabular}

Este resultado corrobora o de outra pesquisa que, em 1993, avaliou 2980 crianças de 1 a 11 anos atendidas em unidade básica de saúde localizada na mesma região de nosso estudo ${ }^{(19)}$. Neste, a maior freqüência de dificuldades ocorreu em crianças de 3 a 6 anos, com ênfase da linguagem oral nas de 3 . Para a autora, uma possível explicação seria a

imaturidade neurofisiológica para a aquisição e domínio da linguagem e também, aos fatores sociais relacionados à estimulação necessária para que os padrões lingüísticos se desenvolvam.

Em nosso caso levamos em conta especialmente este último e consideramos a interação da educadora e dos familiares com a criança, lembrando que, acerca destes não temos informações.

Até os 2 anos e 11 meses as proporções educadora/criança estão adequadas, porém após os 3 anos, justamente a idade alterada, esta relação aumenta chegando a 13-15 crianças por educadora, ao invés das 10 recomendadas ${ }^{(20)}$. Vale ressaltar que as creches têm educadoras avulsas que auxiliam nos momentos de excesso de trabalho e eventualmente substituem educadoras ausentes. Não as consideramos nos cômputos por que são compartilhadas por várias salas.

É uma característica destas creches o empenho em desenvolver a autonomia da criança. Percebe-se, acompanhando a rotina da instituição, que as crianças desta fase parecem depender menos das educadoras, que, no entanto, estão sempre perto e focalizadas nas suas necessidades. Assim, é possível concluir que a autonomia das crianças nesta idade as torna mais suscetíveis em termos de desenvolvimento da linguagem, e que a interferência ambiental, ou seja, a menor proporção educador por crianças, pode contribuir para incrementar esta vulnerabilidade. Aliás, estudos têm mostrado que as crianças não estão exercendo todas as suas potencialidades no que diz respeito à linguagem e isto vêm ocorrendo em diversos contextos: creches públicas, universitárias e, inclusive, escolas privadas ${ }^{(10,21-23)}$. 
No entanto, temos sempre em mente que o estudo tem limitações devido ao pequeno tamanho da amostra e ao fato de não ter sido desenhado de modo a definir as respectivas influências das creches e das famílias. No que diz respeito à estas últimas lembramos, como exemplo, que aumento da escolaridade materna corresponde também a aumento significativo de conhecimentos sobre o desenvolvimento das habilidades de linguagem da criança ${ }^{(24)}$.

Finalmente as informações obtidas nas 3 avaliações foram analisadas quanto aos sexos sem que houvesse diferença significante (Teste exato de Fisher $\mathrm{P}=0,469$ ) o que corrobora alguns autores ${ }^{(15,16)}$, mas não outros ${ }^{(18,25)}$.

\section{CONSIDERAÇÕES FINAIS}

Vale ressaltar que os resultados das 2 áreas foram diferentes, o que também foi evidenciado em um estudo comparativo entre crianças de creches públicas e privadas da cidade de São Paulo ${ }^{(26)}$. As crianças tiveram desenvolvimento semelhante na área cognitivo-social, mas na linguagem as de creches públicas apresentavam ritmo de desenvolvimento mais lento, resultado atribuído ao menor nível de escolaridade das educadoras e das mães. Isto reforça a importância de condições favoráveis para criança desenvolver-se plenamente.

Outra pesquisa, também realizada em creche pública da cidade de São Paulo, igualmente detectou o quanto as crianças estavam sendo afetadas na área de linguagem ${ }^{(22)}$. Nos 3 grupos analisados (12 a 23 meses, 24 a 35 meses e 36 a 47 meses) as alterações foram respectivamente $57 \%$, 46\% e 50\%. A área pessoal-social foi menos afetada, tal como em nosso trabalho.

Em nossa coorte a área pessoal-social parece que não sofreu influência da proporção adulto/criança. Até que ponto este resultado se deve somente a esta última não se pode dizer, mas, considerando que nestas instituições as crianças permanecem durante todo o dia, freqüentar a instituição não as prejudicou. Isto é importante uma vez que se sabe que ambientes adequados potencializam tanto as habilidades de linguagem quanto as cognitivas, de acordo com estudo realizado nos Estados Unidos, com uma coorte de 1158 crianças avaliadas em 10 cidades diferentes ${ }^{(17)}$.

Quanto à área de habilidades de linguagem, aparentemente não houve qualquer modificação por freqüentarem as creches. Isto pode ser interpretado de dois modos: ou já estavam em um bom patamar ao começarem a freqüentá-las, ou as instituições não estão favorecendo o desenvolvimento máximo das potencialidades das crianças. A primeira possibilidade não é plausível: havia 7 crianças (23,3\%) em 30 com cautelas e atrasos, sendo 7 cautelas e 2 atrasos. Na área pessoal-social estas mesmas 30 crianças apresentaram 5 cautelas e 1 atraso. Estes dados foram emparelhados e comparados usando-se teste de Wilcoxon, cujo resultado não foi significante. Para a aplicação do Wilcoxon atribuiu-se escore 3 (três) para adequado, 2 (dois) para 1 cautela ou 1 atraso e 1(um) para 1 cautela+1 atraso.

Isto é, como as crianças ao ingressarem na creche estavam com desenvolvimento semelhante nas áreas pessoal-social e de linguagem, e na primeira melhoraram significativamente após cerca de 6 meses, esperava-se que o mesmo ocorresse na área de linguagem. Isto não ter ocorrido sugere a possibilidade de que o desenvolvimento pleno não foi alcançado.

\section{CONCLUSÕES}

As habilidades das crianças na área pessoal-social melhoraram significativamente após terem começa- do a freqüentar as creches. No entanto, as habilidades da área de linguagem não apresentaram os mesmos resultados. Não se pode afirmar a causa destes acontecimentos, embora seja intrigante a proporção adulto/criança que diminui após as crianças completarem 3 anos de idade. Além disto, vê-se que esta diminuição afeta a área de linguagem, mas não a pessoal-social, o que é curioso uma vez que a criança é bastante dependente de outros para o desenvolvimento de ambas. Por este motivo pretende-se complementar este trabalho com outro, a fim de definir as respectivas esferas de influências da família e da instituição. De qualquer modo gostaríamos de frisar que é uma tentativa de demonstrar o quanto a supervisão do desenvolvimento é uma ação de saúde importante, e deve ocorrer seja qual for o ambiente em que a criança vive. Sabe-se que atualmente, em nosso país, são pouquíssimas as instituições de educação infantil que fazem acompanhamento sistematizado do desenvolvimento infantil, mas ressaltamos que esta ação de saúde é necessária e este pequeno trabalho foi realizado para ajudar a demonstrá-lo.

\section{AGRADECIMENTOS}

Ás crianças que estão participando deste trabalho, a seus responsáveis, aos funcionários das instituições envolvidas, à Profa.Dra.Márcia Pedromônico da Disciplina "Distúrbios da Comunicação Humana” da UNIFESP-EPM (São Paulo) pela permissão do uso do formulário do TTDD II traduzido por ela e sua equipe, à Fernanda Guedes Lima que participou voluntariamente em parte do trabalho, à FAPESP e ao CNPq. 


\section{REFEFÊNCIAS}

1. Ministério da Saúde. Secretaria de Políticas de Saúde. Atendimento integrado à saúde e desenvolvimento da criança: módulo 1. Cartão da criança. Brasília; 1995.

2. Ministério da Saúde. Secretaria de Políticas de Saúde. Saúde da criança: acompanhamento do crescimento e desenvolvimento infantil. Brasília; 2002. (Cadernos de Atenção Básica, n.11; Série A. Normas e Manuais Técnicos, n.173).

3. Organización Panamericana de La Salud (OPAS). Promoción del crescimiento y desarollo integral de niños y adolescentes: módulos de aprendizaje. Washington; 1999.

4. Oliveira ZM. Creches: crianças, faz de conta \& cia. 6.ed. Petrópolis: Vozes; 1998. cap. 3, p.27-37.

5. Shore R. Repensando o cérebro: novas visões sobre o desenvolvimento inicial do cérebro. Trad de Iara Regina Brasil. Porto Alegre: Mercado Aberto; 2000.

6. Ministério da Educação e do Desporto. Secretaria de Educação Fundamental. Referencial Curricular Nacional para a Educação Infantil. Brasília; 1998.

7. Vygotsky LS. A formação social da mente. 4a ed. São Paulo: Martins Fontes; 1991. cap.1, p.21-33.

8. Berquo ES, Souza JMP, Gotlieb SLD. Bioestatística. São Paulo: EPU; 1981.

9. Frankenburg WK. Does Denver II produce meaningful results? Pediatrics 1992; 90(3): 477-9.

10. Rezende MA. Habilidades de linguagem e pessoal social de crianças de $0 \mathrm{a}$ 3 anos de idade cuidadas em creches. Rev Bras Cresc Desenv Hum 2003; 13(1):40-52.

11. Frankenburg WK, Dodds J, Archer P, Shapiro H, Bresnick B. Denver II: training manual. Denver: Denver Developmental Materials; 1992.

12. Hollander M, Wolfe DA. Nonparametric statistical methods. 2nd ed. New York: John Wiley \& Sons; 1999.
13. Siegel S. Estatística não-pramétrica para as ciências do comportamento. São Paulo: Mc Graw-Hill; 1975.

14. Issler RMS, Giugliani, ERJ. Identificação de grupos vulneráveis à desnutrição infantil pela medição do nível de pobreza. J Pediatr 1997; 73:101-5.

15. Halpern R, Barros FC, Horta BL, Victora CG. Desenvolvimento neuropsicomotor aos 12 meses de idade em uma coorte de base populacional no sul do Brasil: diferenciais conforme peso ao nascer e renda familiar. Cad Saúde Publica. 1996 12:73-8.

16. Cunha HL. Desenvolvimento de crianças atendidas no hospital de pediatria da Universidade Federal do Rio Grande do Norte no primeiro ano de vida: aplicação do teste de Denver II em ambulatório. [dissertação mestrado]. São Paulo: Escola Paulista de Medicina, Universidade Federal de São Paulo; 2000.

17. National Institute of Child Health and Human Development Early Child Care Research Network. The relation of child care to cognitive and language development. Child Dev 2000; 71(4):960-80.

18 Durmazlar N. Turkish children's performance on Denver II: effect of sex and mother's education. Dev Med Child Neurol 1998; 40(6):411-6.

19. Andrade CRF. Prevalência das desordens idiopáticas da fala e da linguagem em crianças de um a onze anos de idade. Rev Saúde Pública 1997; 31(5):495-501.

20. Secretaria do Menor. Creche/Pré-escola. São Paulo; 1992.

21. Toledo MNC. Mãe! E agora, o que é que eu falo? Avisalá 2000; 1(2): 2730 .

22. Souza ABG, Siqueira CN. Avaliação do desenvolvimento de um grupo de crianças assistidas em creche, usando o teste de triagem de Denver II. Enferm Brasil 2003; 2(2): 96-103.
23. Costa PS, Pontes PB, Rezende MA. O desenvolvimento infantil em creches e pré-escolas segundo o Teste de Triagem de Desenvolvimento de Denver II (TTDD II). [Relatório de pesquisa] São Paulo: Escola de Enfermagem da USP; 2004.

24. Cardoso RM. Conhecimento de mães e auxiliares de desenvolvimento infantil referentes ao desenvolvimento de linguagem de crianças de 0 a 24 meses de idade. [dissertação mestrado]. São Paulo: Escola Paulista de Medicina, Universidade Federal de São Paulo; 2001.

25. Pedromônico MR, Affonso LA, Sãnudo A. Vocabulário expressivo de crianças entre 22 e 36 meses: um estudo exploratório. Rev Bras Cresc Desenv Hum 2002; 12(2):13-22.

26. Ramos CS, Pedromônico MRM, Shinzato AR, De Lucas S. Comparação do desenvolvimento do comportamento de crianças de creches públicas e particulares no segundo ano de vida. Pró-Fono 2002; 14(3):401-8. 
Rezende MA, Beteli VC, Santos JLF. [Evaluation of language and personal social abilities by the Denver Test II in institutions of infantile education.] Acta Paul Enferm 2005; 18(1):56-63.

ABSTRACT: Supervision and promotion of development are important care given to children enrolled in day-care centers and pre-schools. International and national organisms have systematized strategies to supervise child development but in Brazilian day-care centers this action is not well performed. Objective: To assess, after a two-year follow-up, personal and social language abilities in a cohort of children enrolled in three day-care centers, in the city of São Paulo. Methods: The sample group consisted of 30 children from 0 to 4 years, of a homogeneous socioeconomic level according to the tool of evaluation of urban poverty level. According to this tool all the families were in the upper level of the assessment. To evaluate the child development was used the Denver II, applied at two different moments, in the first year of follow-up of the cohort and once in the second year. Results: In the personal and social areas, a significant improvement difference was observed from the $1^{\text {st }}$ to the $2^{\text {nd }}$ evaluation. In the language area no differences could be observed among the three evaluations, although age had a significant role as 3-year old children presented the worst results. Regarding sex, no significant differences were observed in the performance of the two areas. Conclusion: It is possible that performance in the personal and social areas has been improved by the day-care center conditions, what didn't happen in area of language. Regarding this area, it could be affected by the adult/child ratio as with children older than 3 years, but further researches are needed inclusive continuity to this cohort.

Descriptors: Child day-care centers; Child rearing; Child care; Child development; Child language
Rezende MA, Beteli VC, Santos JLF. [Evaluacion de habilidades de lenguaje y personal-sociales por el Test de Denver II em instituiciones de educacion infantil.] Acta Paul Enferm 2005; 18(1):56-63.

RESUMEN: La supervisión y promoción del desarollo infantil son cuidados necesários a los niños que frequentan jardines infantiles y pré-escolares. Las organizaciones de salud internacionales y nacionales tienem sistematizado estratégias para tal, pero en jardines infantiles y pré-escolares brasileñas esa ación és poco realizada. Objetivo: evaluar por el segundo año consectivo, habilidades de las áreas de lenguaje y personal-social de uma cohorte de niños que frecuentan 3 jardines infantiles de la ciudad de São Paulo. Metodo: el grupo estudiado fué conformado por 30 niños desde los cero hasta los cuatro años, de nivel-sócio econômico homogeneo según instrumento para evaluación de nivel de pobreza urbana. Según este instrumento todas las famílias estaban en la faja superior de clasificación. Para evaluación del desarollo fué utilizado el Test de Triage de Desarollo de Denver II, empleado en dos momentos distintos en el primer año de acompanhamiento de la cohorte y una vez en el segundo año. Resultados: en el área personal-social la mejora fué significativa de la $1^{\mathrm{a}}$ para la $2^{\mathrm{a}}$ evaluación, lo que no ocurrió en el área de lenguaje a lo largo de las 2 evaluaciones. Por lo tanto, a partir de los 3 años de edad los niños pasaron a obtener resultados peores. En cuanto a los sexos no hubo diferencias significativas en los desempenhos de las dos áreas. Conclusión: és possible que las habilidades de los niños en el área personal-social hayan sido incrementadas por las condiciones de las instituiciones, lo que no ocurrió en el área de lenguaje. No se puede afirmar la causa de estos acontecimientos, aunque sea intrigante la proporción adulto/niño que disminuye después de que los niños cumplen 3 años de edad, pero otras investigaciones son necesárias aun la continuidad de esta cohorte.

Descriptores: Jardines infantiles; Crianza del niño; Cuidado del niño; Desarollo infantil;Lenguaje infantil 